\title{
Pupils' ways of understanding programmed technological solutions when analysing structure and function
}

\author{
Anne-Marie Cederqvist ${ }^{1}$
}

Received: 10 June 2019 / Accepted: 2 September 2019 /Published online: 13 September 2019

(C) The Author(s) 2019

\begin{abstract}
Programming has recently become part of Swedish technology education; pupils should now be able to analyse existing programmed technological solutions, and be able to design new ones. Teachers facing this curriculum change need guidance on how to teach and what to address, based on how pupils understand the content. The aim of this study is to investigate pupils' different ways of understanding programmed technological solutions when analysing their structure and function. Taking a phenomenographic approach, interviews were conducted with pupils aged 11-12. In the interviews, prepared contexts were used: Micro:bit constructions and programmed technological solutions from everyday life. The results show that pupils have different approaches to programmed technological solutions based on what parts are discerned in the prepared contexts, and also that pupils approach the two prepared contexts differently. The parts that are critical to discern in both of the contexts are the physical structure of components in the technological solution, how the components work and what their function is in the solution, as well as the logic in the code and how it controls the components and the flow of information that determines the function of the solution. The discernment of these parts is necessary to transcend the contextual details and generalize the understanding of structure and function in programmed technological solutions. These results have implications for teaching with concrete programming materials, suggesting a need to focus on facilitating discernment of the parts and addressing the similarities and the differences between different contexts in order to reach a generalized understanding.
\end{abstract}

Keywords Programming $\cdot$ Technology education · Primary pupils $\cdot$ Programming materials $\cdot$ Technological solutions $\cdot$ Systems thinking

Anne-Marie Cederqvist

anne-marie.cederqvist@gu.se

1 Department of Pedagogical, Curricular and Professional Studies, University of Gothenburg, P.O. Box 300, 40530 Gothenburg, Sweden 


\section{Introduction}

The winds of change are blowing through education systems worldwide (Balanskat and Engelhardt 2015; Hubwieser et al. 2014). Digital technology has a great impact on people's daily lives and hence it needs to be a part of education (Skolverket 2017a). Several countries have already revised their curricula to provide opportunities for pupils to develop digital competence that can meet the demands of future digital technology and future labour markets. In most countries, programming has been highlighted as an important part of the development of digital competence and, in some cases, implemented as a separate subject (Balanskat and Engelhardt 2015). In the revised curriculum for the Swedish compulsory school (Skolverket 2017b), it was decided to not implement programming as a separate subject but instead to integrate it into different subjects such as mathematics and technology.

Within technology education, an overall aim is to develop pupils' understanding of technological solutions in everyday life. Digital technology and programming have been implemented as a part of this aim, which is bi-directional: pupils should be able to identify and analyse the structure and function of existing technological solutions, and also design their own solutions, which includes controlling them with programming (Skolverket 2017b). However, many teachers facing curriculum changes that include programming experience an uncertainty about how to teach (Sentance and Csizmadia 2017; Webb et al. 2017), and there is a scarcity of didactical research to guide them (Passey 2017).

In order to guide teachers on how to teach regarding programming and technological solutions, it is necessary to learn more about how pupils understand programmed technological solutions. There are a few studies (Mioduser et al. 1996; Slangen et al. 2010) that investigate pupils' understandings when designing their own technological solutions with programming materials, such as LEGO kits, and controlling them with programming. These studies show that pupils have difficulties understanding how to program in relation to the function of the components, which results in pupils avoiding certain functions in their designs, as a result of not being able to manage the programming needed. Even if they understand the function of the components, they lack an understanding of how the components interact and how the programming controls the technological solution. These difficulties limit the pupils' ability to design the technological solutions desired. There are also studies where pupils are introduced to digital technology and programming with different programming materials, that report that pupils have difficulties making connections between programming materials and the abstract phenomena the materials represent (Ivarsson 2003; Kalelioglu 2015; Kalelioglu and Gülbahar 2014). Further, several studies report that programming is difficult to learn (McCracken et al. 2001; Robins et al. 2003; Rolandsson 2015), and even if younger pupils are introduced to programming with block-based programming, it is still difficult to learn (Grover and Basu 2017). It has also been suggested that pupils cannot learn about digital technology and programming by trial and error (Rush Hovde and Renguette 2017): they need guidance from the teacher to discern what the programming materials represent (Ivarsson 2003; Lye and Koh 2014; Pea 1983; Rolandsson 2015).

Previous studies indicate that pupils have difficulties in understanding both the programming, and the structure and function of a programmed technological solution, 
and teachers need appropriate knowledge of how to deal with these difficulties. However, there is a scarcity of research about how pupils' understandings are constituted and what to address in teaching (Kjällander et al. 2016). The present study, where pupils' different understandings of programmed technological solutions are investigated, may therefore provide an important contribution to knowledge about how pupils' understandings are constituted, which forms an important foundation for organizing teaching.

\section{Making programmed technological solutions understandable}

\subsection{Understanding technology and technological solutions}

When technology is discussed, it can have several different meanings. It can refer to objects, activities, areas of knowledge and so on. Carl Mitcham (1994) addresses four different ways of describing technology: technology as actions, which is the work of designing, constructing, troubleshooting etc.; technology as knowledge, the knowledge and skills used in the work; technology as volition, the forces that drive the work forward; and technology as objects, which in this study refers to the technological solutions that the work results in. Technology can then be defined as a human activity that, by using knowledge and the natural environment, fulfils human needs (de Vries 2005).

Technology is met in a variety of technological solutions in daily life, such as mobile phones, computers, remote controls, internet, cars and so on. Today, these solutions are more complex than they have ever been and much more integrated into people's lives than before. There are technological solutions that, by being a part of a human's body, such as a pacemaker, are vital. People are dependent on technological solutions such as water supply systems to be able to survive, and electrical supply systems and the Internet to make societies function. Common to these is that they all have a structure and a function that fulfil a need. The function is related to human intentions and the need to change something from one state into another with the help of a technological solution (de Vries 2005). The function is, however, dependent on an appropriate physical structure. When designing a technological solution, the point of departure is the desired function. To realize this function, a particular physical structure of components in the technological solution is needed. The technological solution therefore has a dual nature: a functional nature and a physical nature (de Vries 2005).

\subsection{Understanding technological solutions by using systems thinking}

When doing the opposite of designing, i.e. examining a technological solution to understand what it does and how it is built, systems thinking can be used to understand its physical structure and its function. The technological solution is then seen as a technological system that can be described as follows: there is a need that the system meets; the system consists of a number of components and there is a connection between these components; these components form a whole; there is also a system limit that separates the system from the environment; however, in most cases, the system has a relation to the environment (Ingelstam 2012). In all kinds of technological systems, there 
is some kind of movement; there is a flow. The different types of flows in technological systems are energy, information and matter. To generate a flow, different processes and components are used and there are connections between them; they interact with each other. In systems with many components, some of the components can be considered to be black boxes. This means that you do not describe what is happening inside these components. Instead, you describe what is moving in and out of a component or a black box. The components fulfil some kind of function in the technological system, which can be to transform, transport, store or control the flow, which in the end determines the function of the technological system. This way of seeing the parts of a technological solution facilitates the analysis of its structure and function.

An overall aim in technology education is to develop pupils' knowledge about technological solutions in everyday life. They are expected to identify and analyse the structure and function of technological solutions but also to be able to develop their own technological solutions. The variety of technological solutions pupils meet in everyday life can, however, be difficult to understand from a structural and functional perspective. To make these technological solutions understandable, a systems-thinking perspective can be applied, where pupils see the technological solution as a technological system. However, previous studies show that pupils have a limited understanding of how technological systems are structured and function (Booth Sweeney and Sterman 2007; Koski and de Vries 2013; Svensson 2011). Pupils experience a technological system where, for example, a mobile phone is included, as opaque and difficult to understand in its entirety, despite using this technological system daily. Pupils approach technological systems from a user-driven perspective, where the focus is on what can be seen and what the technological system does, based on their experience of it (Koski and de Vries 2013). These previous studies point out the importance within technology education of focusing on developing pupils' systems thinking (Booth Sweeney and Sterman 2007; Koski and de Vries 2013; Svensson 2011), which can be seen as depending on three overall skills: understanding the components of the system, understanding how the components interact and understanding the system as a whole (Booth Sweeney and Sterman 2007).

\subsection{Understanding programmed technological solutions}

Since many technological solutions of today are controlled by programming, pupils also need to be able to understand programming as a part of a technological solution. In order to make a programmed technological solution work in the way you want, programming is used to control the components and the flow of information between them. The program, or the code (which is used as a synonym in this article), can be seen as a immaterial component that involves instructions or information, stored in a material component, the processor. The other components in the technological solution, such as buttons, sensors, speakers etc., are connected to the processor and have the function of handling the flow of information in a way that is determined by what is written in the code. Hence the code includes information about how each component will function and how it will handle the flow of information in the technological solution. The components are structured in a way that makes it possible for them to interact and move information between themselves to fulfil the function of the technological solution. 
There are a few studies where teaching and learning about the design and control of programmed technological solutions are investigated. These show that pupils have difficulties in understanding the flow of information, as well as the entire chain of control functions and how the components interact with each other, especially in closed-loop systems where feedback controls the flow (Mioduser et al. 1996; Slangen et al. 2010). These studies also show that pupils need a lot of guidance from the teacher when designing technological solutions that include programming, since they have difficulties in understanding how to program the solutions. The teacher's guidance reduces the cognitive load devoted to managing the task, but at the same time limits the pupils' opportunities to develop an understanding of digital technology (Ginestié 2018). Previous studies indicate that knowledge about, and skills in, programming are important when designing a programmed technological solution. There is, however, as Ginestié also points out, a debate about whether pupils learn this by discovering on their own or by being instructed by the teacher.

Introducing programming in education for younger pupils is not a new phenomenon: similar approaches have been used before. Seymour Papert introduced Logo, a minilanguage with an easier syntax and semantics, for younger pupils in the 70s. He had the vision that when pupils were taught programming, they would develop a general problem-solving ability that would also be useful within other subjects (Papert 1993). However, when Pea and Kurland (1984) conducted a study where they investigated pupils' understanding of programming after programming with Logo, the results showed that the pupils had still difficulties in understanding and learning basic concepts in programming. There are also several studies that have reported that students at secondary and university level have difficulties in learning programming (e.g. McCracken et al. 2001; Robins et al. 2003; Rolandsson 2015). Although younger pupils today are usually introduced into visual programming with the help of so-called 'blocks' that make it syntactically easier to work with programming, the semantic problems related to the understanding of concepts represented by the blocks remain unsolved (Grover and Basu 2017). Other studies (Ivarsson 2003; Kalelioglu and Gülbahar 2014; Kalelioglu 2015) show that pupils manage to handle programming materials and solve relatively advanced problems with the support of the materials but that they have no deeper understanding of the concepts the materials represent and therefore have difficulties in solving similar tasks in other problem-solving situations. Pupils cannot learn the basic concepts in programming by using only trial and error when managing programming materials (Rush Hovde and Renguette 2017). They do not manage to make relevant connections between concrete programming materials and the abstract concepts represented by the materials, and therefore the teacher plays an important role by guiding, visualizing and helping the learner to understand the abstract concepts that the materials represent (Ivarsson 2003; Lye and Koh 2014; Pea 1983; Rolandsson 2015). Pupils have misconceptions when they are learning to program that must be addressed by the teacher (Grover and Basu 2017).

It seems that programming is difficult to learn and that pupils have difficulties in understanding programmed technological solutions. Despite this, there is a scarcity of studies that provide deeper insight into how pupils' understandings are constituted and which parts are difficult for them to understand. Hence the aim of the present study is to investigate how pupils, aged 11-12, understand programmed technological solutions, when identifying and analysing the structure and function of different programmed 
technological solutions. The results will provide an important basis for what teachers need to address in teaching in order to develop pupils' understandings of programmed technological solutions and digital technology.

\section{Methodology and research design}

To gain insight in pupils' qualitatively different ways of understanding programmed technological solutions, the study was carried out with a phenomenographic approach. Semi-structured interviews were used together with prepared contexts ${ }^{1}$ involving programmed Micro:bit ${ }^{2}$ constructions and programmed technological solutions from everyday life.

\subsection{The phenomenographic approach}

Phenomenography describes knowledge as a way of experiencing and understanding the world (Marton and Booth 1997; Marton 2015). There are variations in individuals' ways of understanding a phenomenon that are related to the differences in what is discerned. When something is learned, there is a change in the relationship between the individual and the phenomenon that is studied, and the phenomenon is understood in a new way. It can be that the parts of the phenomenon, the relationships between the parts, and how they relate to the whole of the phenomenon are discerned in a new way. This is the structural aspect of understanding the phenomenon. The change is also related to the discerned meaning of the phenomenon, the referential aspect. Marton and Booth describe these two aspects as closely intertwined and that they are present in the individual's awareness at the same time when a phenomenon is understood. The parts of a phenomenon are discerned from what is present for the individual. What is understood is then based on the individual's senses and perceptions, such as seeing and hearing. But the phenomenon may also be understood from parts that are not presented, that are in the individual's awareness due to previous experience, i.e. these parts are appresented. According to Marton and Booth, appresentation refers to: “...the fact that although phenomena are, as a rule, only partially exposed to us, we do not experience the parts as themselves, but we experience the wholes of which the parts are parts." (Marton and Booth 1997, p. 100). Thus, even if not all the parts of a phenomenon are exposed, the individual can still understand the whole of the phenomenon based both on what is presented and what is appresented.

By examining the variation in the understanding of a phenomenon in different contexts, based on the discerned structural and referential aspects, important aspects can be identified that enable learning. Marton and Booth (1997) describe these as critical aspects of a phenomenon, and when several of these are distinguished at the same time, it usually represents the most complex way of understanding a

\footnotetext{
${ }^{1}$ A prepared context can be a concrete object or a photo that is used to highlight the phenomenon in a context that is familiar to the pupil and is defined as: “... what the researchers considers to be relevant for the interviewee to make sense of the situation at hand." (Adawi et al. 2001, p. 4).

${ }^{2}$ The programming material Micro:bit is a small microcontroller with a built in LED display and sensors, which can be programmed with blocks as well as text-based programming. The Micro:bit can also be connected to other components such as motors, sensors, and speakers to construct different technological solutions.
} 
phenomenon. In order to generalize the understanding of a phenomenon, the learner has to discern aspects of the phenomenon in different contexts; thus to be able to generalize the understanding of a phenomenon and transfer it to new contexts, the learner has to see the phenomenon in two or more different but connecting contexts, where the learner uses an understanding based on the discerned aspects of the phenomenon from the previous context to see the differences and similarities between the two contexts (Marton 2006).

It is not pupils' individual understandings of the phenomenon that constitute the main research interest in this study but the variation in possible understandings. These different ways of understanding can be considered more powerful or less powerful in relation to specific criteria: the structural and referential aspects. By arranging pupils' different understandings in qualitatively distinct hierarchical categories, the individual understandings can be raised to a more general level. The distinct categories constitute the outcome space which is the result of the phenomenographic study.

\subsection{Data collection}

Data was collected through semi-structured interviews. The interviews were held with 23 pupils, 12 in fifth grade and 11 in sixth grade, aged 11-12, at two different Swedish compulsory schools. All pupils have been taught programming by using different concrete programming materials like LEGO Mindstorm, Micro:bit, Scratch and LEGO WeDo by teachers who have used programming in their teaching for several years. The interviews were conducted in Swedish, recorded individually in a separate room beside the classroom during school hours and lasted for about 20-30 min.

\subsubsection{The interview questions and the prepared contexts}

The questions in the interview were developed with the aim of investigating pupils' understandings of programmed technological solutions. An interview protocol was used with a number of questions that revolved around the function and structure of programmed technological solutions and possible problems when constructing them that would cause them not to function. The interview protocol had been pilot tested on a number of pupils and subsequently revised before conducting the interviews.

In the interview, prepared contexts were used with the purpose of facilitating the pupil in answering the interview questions by framing and highlighting the phenomenon (programmed technological solutions) in familiar contexts (Adawi et al. 2001). This increases the possibility of obtaining a more varied picture of how pupils understand the phenomenon. The prepared contexts in this study represent contexts where the phenomenon exists: two Micro:bit constructions and three programmed technological solutions from everyday life that should be familiar to the pupils. These contexts were chosen on the basis of the aim in the syllabus for technology: that pupils should be able to identify and analyse the structure and function of technological solutions.

The prepared contexts are illustrated below. In the case of the Micro:bit constructions, a code was also shown on the computer screen for each of the constructions, "The Name Badge" (Fig. 1) and "The Burglar Alarm" (Fig. 2). In the context of the programmed technological solutions in everyday life, a car key, a remote control and a thermometer were used (Fig. 3). 


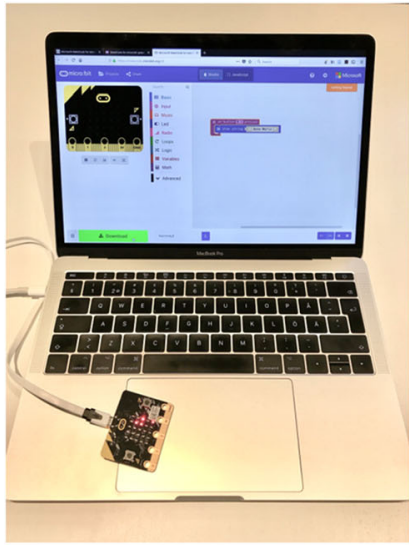

\section{o on button $A-$ pressed}

\section{\#\# show string 6 Anne-Marie 9}

Fig. 1 The Name Badge: The Micro:bit construction with associated code on the screen

The examples of programmed technological solutions were placed in front of the pupil during the interview while questions were asked. In the interview protocol, a final section was also included where the pupil had the opportunity to bring up other programmed technological solutions from everyday life and describe how they are structured and function.

\subsubsection{Ethical issues}

This study explores pupils' ways of understanding a phenomenon by interviewing pupils aged 11-12. Consent was obtained from all concerned, such as pupils, parents, guardians, teachers and principals. Initially consent was sought from teachers and principals at the two participating schools by emailing them information about the nature of the study and in what way the pupils would take part, as well as issues concerning confidentiality and self-determination. After the teachers and the principal agreed to participate, the pupils and their parents were informed by providing them with a letter of consent. The letter of consent contained information regarding the purpose and the outline of the study as well as the nature of the participants' involvement, confidentiality, self-determination and the possibility of withdrawing from the
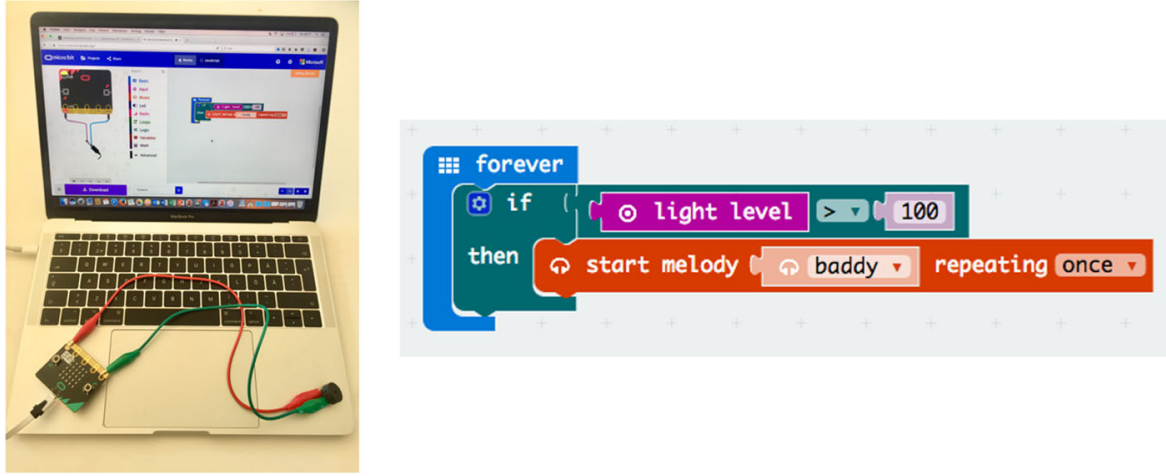

Fig. 2 The Burglar Alarm: The Micro:bit construction with associated code on the screen 

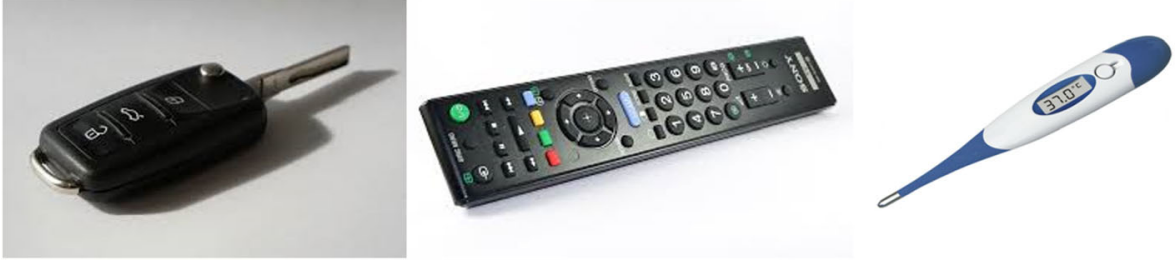

Fig. 3 The programmed technological solutions in everyday life

study at any time. Before the interviews were held, the researcher informed the pupils about the study and how it would be conducted. The pupils were also informed that they had the option to withdraw from the study at any time.

\subsubsection{Limitations of the study}

Phenomenography is a qualitative research approach where the core knowledge claim is to map and characterize the variation in understanding the same phenomenon. In this study, semi-structured interviews were held with 23 pupils to explore their ways of understanding programmed technological solutions in depth. Trigwell (2006) argues that a sample of between 10 and 30 interviews is sufficient to capture most of the variation in understanding a phenomenon, which is based on the idea that there is a limit to the number of qualitatively different ways of understanding a phenomenon (Marton and Booth 1997). The sample size in this study is not adequate to conduct an analysis in a quantitative way. However, the number of interviewees, and the variation in how they understand the same phenomenon, provide a sufficient and important insight into the variation of understandings within this group of pupils. The results of the study may be related to other contexts, taking the information regarding the study context given into account. The relevance of the study is in the end determined by the ways in which and the contexts in which it turns out to be useful.

\subsection{Analysis}

The process of analysis started with producing verbatim transcripts of the interviews. All the transcripts were then read repeatedly to get an overall picture of the content. From this reading, it seemed that the pupils had different approaches to programmed technological solutions, depending on which prepared contexts the pupils were discussing: the programmed Micro:bit constructions and the programmed technological solutions in everyday life. Hence the initial analysis was divided into two parts based on these two contexts.

The transcripts from each part of the interviews were first read repeatedly. Then excerpts were selected that represented pupils' different understandings of the phenomenon investigated, i.e. programmed technological solutions. These excerpts were interpreted and brought together into different categories. The categories were then analysed and defined in terms of the structural and referential aspects that constituted the understanding in each category. Then the data were tested against the defined categories in order to adjust the definition of the categories. Pupils' different understandings constituted two outcome spaces or two sets of categories (one for 
programmed Micro:bit constructions and one for programmed technological solutions in everyday life), each with four different categories. Finally, the two sets of categories were compared to each other to find similarities and differences and then integrated to a common outcome space. The categories are qualitatively different from each other but logically and structurally related to each other in terms of increasing complexity.

\section{Results}

The results below are reported in three parts based on the analysis. First, the two sets of categories are described. Second, the discerned structural and referential aspects are described for each category in the two sets of categories. Third, the common outcome space is described, as well as the critical differences between the categories, i.e. the critical aspects.

\subsection{Outcome space A - pupils' understandings of programmed micro: bit constructions}

In the interviews, the two Micro:bit constructions "The Name Badge" and "The Burglar Alarm" were put in front of the pupil, one at a time, together with the associated codes on the computer screen, while questions were asked about the programmed Micro:bit constructions. The categories developed during the analysis describe qualitatively different ways of understanding programmed Micro:bit constructions.

\subsubsection{Categories}

1. The code and the device ${ }^{3}$ interact

2. The code and components interact

3. A flow is generated by the interaction

4. The flow of information determines the function

1. The code and the device interact In this category, the whole of a technological solution is vaguely discerned as a device with a function, without discerning the components. There is no clear understanding of what the code and its structure represent, and in addition to not seeing the structure of components, the pupils have difficulties in understanding the purpose of the code and the function of the components in the technological solution. The excerpts in this category indicate that pupils are not able to explain the meaning of the concepts IF and THEN, which is crucial for understanding how the code and the components interact in the case of the burglar alarm. When the pupil in the excerpt below describes the meaning of the part of the code with the light level and start melody (see Fig. 2), it appears that there is a lack of understanding of this part of the code as well. Further, the pupil is not able describe

\footnotetext{
${ }^{3}$ The English word "device" is commonly used in Swedish, both by the pupils in the study and in the Swedish educational context. It can be seen as a synonym for an apparatus or a machine. In this study, the pupils use the word "device" to refer to the Micro:bit construction.
} 
how the code and the structure of components will affect what happens in the Micro:bit construction.

Interviewer: What does this mean?

Pupil 12: FOREVER is that it will run over and over continuously.

Interviewer: And this, IF and THEN?

Pupil 12: I don't really know.

Interviewer: No, what does this say?

Pupil 12: Light...light level to a hundred then. And then start ... then a melody starts, repeats once.

Interviewer: What does that mean?

Pupil 12: That there should be a light like over the fridge and then that there will be a melody instead of a kind of beep beep that beeps continuously.

Interviewer: [...] what will happen here in the construction with the Micro:bit and the speaker then? How does that work, do you think?

Pupil 12: I don't really know.

Interviewer: [...] if we think of what's here in the code itself.

Pupil 12: Yes.

Interviewer: And then look at that [the Micro:bit construction], is there any idea...?

Pupil 12: [shakes his head]

[...]

Interviewer: Mm, how does this work then?

Pupil 12: I think you kind of downloaded that [the code] and then it has been transferred over here so when you open then it will shine to level hundred, then it will shine, then you hear the melody here in the speaker.

In the excerpt above, the pupil describes how the code has been transferred to the Micro:bit and how in the end it makes the speaker play the melody. Even though there are parts of the description that are incorrect, there is an understanding of an interaction between the code and the device that affects the function. In the excerpt below, the Micro:bit construction is vaguely discerned as the whole of a technological solution with a particular function, which is activated to do something based on the program, though without the components being discerned. An inability to understand the code and to discern the components might be the reason that pupils have difficulties explaining how the code and the components work together.

Interviewer: No, but if we look at this code and these components that are here, do you think that you could describe for me how they work together? [...]

Pupil 23: So there is a program here that somehow tells that one [the Micro:bit] what to do and then that program is sent through the cable here to this [the Micro:bit] and then what's written in there, that program is somehow made to work with that device. So it's sent to that one and then it does that...so the signal is sent, the program, then it's activated or whatever you want then, depending on what the program looks like it's activated and does what you have programmed it for. 
2. The code and components interact This category differs from Category 1 in that the excerpts include descriptions of what the code and its structure represent. The excerpts in this category indicate that the components and how they work are discerned. The excerpts also indicate an understanding of how the code and the components interact based on the logic in the code and how the components work, which affect the function of the technological solution. The excerpts do not indicate any awareness of a flow within the technological solution.

Interviewer: Ok. If you are going to make a construction like this, is there anything that can go wrong when making it?

Pupil 20: Yes, you maybe happen to put the light level there in the code [at THEN], you put them in the wrong place and then maybe it doesn't work.

Interviewer: [...] where could they end up?

Pupil 20: At THEN instead and then the melody ends up at IF.

Interviewer: Ok, what would that mean if you did the opposite? What would...?

Pupil 20: Then maybe if it started to play then the lights are turned on instead.

The pupil above expresses an understanding of the concepts THEN and IF by describing how giving the wrong input in the code will make the technological solution not work or function in a different way. This indicates that the pupil sees what the code and its structure represent and also sees that there is an interaction between the components and the code based on what is written in the code and how the components work, which affects the function.

Interviewer: Yes, and then I wonder how this one knows what to do? [the Micro:bit construction]

Pupil 1: But you've coded it and then you've downloaded the code on the Micro:bit and, like connected it with a speaker like with alligator clips, are they called clips? Or whatever they are called. So that they make it...but it starts then, you can almost say that you told it to do something and then it does that, or that it has a program that it must follow. At that point when it gets brighter, it will start to play and when it gets darker it should be completely dead.

This excerpt indicates an understanding of the interaction between the Micro:bit construction as the whole of a technological solution and the code by saying that the construction has a program that it must follow. But the excerpt also indicates an understanding of how the code and the components interact based on the logic in the code and how the components work. The interaction is seen from two perspectives and the pupil shows an awareness that the interaction affects the function of the technological solution.

3. A flow is generated by the interaction In comparison with Category 2, the excerpts in this category show that the pupils see the structure of components in the technological solution. The pupils also see that a flow is generated by the interaction between the code and the components based on the logic in the code and the structure of components and how this flow affects the function of the technological solution. Excerpts in 
this category indicate that pupils see that there is a flow of something such as light, sound, waves, vibrations or pulses, but they do not see the processes behind this, such as how the code controls the flow or that the function of the components is to handle the flow.

In the excerpt below, the pupil gives a description of how the code interacts with the structure of the components to make things happen. The pupil also explains how a flow, a signal that is described as current, goes around and around through the components and affects them and the function of the solution, but seems unsure of how this works.

Pupil 22: Yes, so that it [the speaker] will make a sound when someone opens the refrigerator and then it [the sensor] senses the light and then there is sound.

Interviewer: [...] look at the code and this construction and its components, the parts, and try to explain for me how this will function.

Pupil 22: Anyway I think that first, the blue up there begins, it's FOREVER and that's what makes it able to do it over and over again.

Interviewer: What do you mean by over and over again?

Pupil 22: Well that [the Micro:bit construction] does that once and then if you close and then open it [the refrigerator] again then that [the Micro:bit construction] can do it again and so it goes on like that. And the 'light level' I think is that it senses bright light [...] And then I also think that when it comes to 'start melody', that's where there is the sound 'baddy' or something, and then whatever it's called, it's repeated once so it's not like played over and over again all the time. But if you close it again and open then it will play the same again.

Interviewer: If we look at these components here, could you describe how this code and these components work together?

$[\ldots]$

Pupil 22: I think first, when you turn it on then the signal goes to the computer through that [the Micro:bit]] because it senses that or yes it senses the light then I think it goes through this first [the wire between the Micro:bit and the speaker] and then it goes to that [the speaker] and plays a sound and then it goes back and then it goes... I don't really know.

Interviewer: What's the last thing you thought that you do not really know, it will go back and then...

Pupil 22: Yes and then the current will remain here.

Interviewer: Yes.

Pupil 22: And then maybe it goes around and around and around ...

In the excerpt below, it can be seen that the pupil describes what is happening within the structure of components in the solution based on what the code and its structure represent. The pupil also describes the interaction between the code and the components as the code 'saying' things to the components, and how there is a special kind of wave that goes through the wires that makes the speaker play a specific melody. This indicates that the pupil is starting to understand that there is a flow of information between the components that has its origin in the code. This flow is described as moving directly between the components without interacting with the code in the 
processor. This indicates that the pupil does not yet see the processes behind the flow where the code controls the flow of information and that the function of the components is to receive and send information from and to the code in the processor.

Interviewer: $[\ldots]$ what will happen in this Micro:bit construction if you look at the code?

Pupil 14: It will sense or then maybe it senses that there is...it gets brighter, then it says through...or like says through these wires to the speaker, since they are like connected and then it will like... begin to play that specific melody because that's what's decided or whatever you say, that is what you want it to do.

Interviewer: Mm, and how does the speaker know when to play?

Pupil 14: Eh, a certain kind of wave goes or whatever it is, maybe it's not a wave, but it goes through the tube... the tubes ... the wires, a special kind of wave goes that it's that particular melody that is going to be played and it will do that.

4. The flow of information determines the function In this category, the excerpts differ from the previous categories in that they indicate a more developed understanding of the different parts of the technological solution. The excerpts in this category indicate that pupils see how a flow of information is generated by the interaction between the logic in the code and the structure of components and that the function of the components is to handle this flow of information. The excerpts in this category do not only indicate an understanding of what the code and its structure represent. They also indicate an understanding that it is the code that controls the flow of information and that determines the function of the technological solution.

The excerpt below indicates an understanding that the function of the Micro:bit construction is determined by the 'info' or sent 'messages', which are based on the interaction between the logic in the code and the structure of components. The pupil describes how information is received and sent on, which is controlled by the program. Further, the function of the components is described when saying that each component has a certain part that can handle information and that the components have to be connected to each other in order to be able to receive and send information between them. This excerpt indicates that the pupil has a more developed understanding of the different parts of the solution and how the code controls the flow of information that determines the function of the solution.

Pupil 6: [...] you've programmed that if it gets bright, that's set to start, well it's always running, but then it understands that it has to make the speaker play music and then it has to send [a signal] to the speaker that it should play that particular melody[...] it receives a lot of info and then it takes that and sends it on.

Pupil 6: $[\ldots]$ there is always something that has to send a signal if anything is going to happen.

Interviewer: $[\ldots]$ what is a signal?

Pupil 6: [...] it may be a message that it sends that 'now you do this', so that everything will function or whatever. 
Interviewer: ....this info you say, where does it end up when it's sent?

Pupil 6: I think it ends up in some programmed things behind those small parts where a lot of different info can be received and then maybe the lamps have a small part, and each component has a certain part, where a certain amount of info can be received that can later be sent forward and so I think it continues.

Interviewer: What do you mean? Everything is connected?

Pupil 6: [...] In the Micro:bit itself, it's ... I think there are a lot of different parts and tubes and everything that are very thin but contain a lot of info and they have to lead somewhere so all of them have to somehow be connected. It is the same from the speaker to the Micro:bit, you cannot just put it next to it, because then the Micro:bit doesn't even know that it's there, it has to be connected in some way...

\subsection{Outcome space B - pupils' understandings of programmed technological solutions in everyday life}

In the interviews, were pupils asked to identified whether different technological solutions are programmed. A car key, a remote control and a thermometer were presented, all at the same time. Each pupil then chose one of the programmed technological solutions and was asked to explain how it works. The pupils also had the opportunity to identify and describe other programmed technological solutions from everyday life. The categories describe qualitatively different ways of understanding programmed Micro:bit constructions.

\subsubsection{Categories}

1. Single components control the function directly

2. Single components interact which involves a flow

3. A code and a flow of information are present

4. The flow of information determines the function

1. Single components control the function directly Excerpts in this category indicate that the pupils understand programmed technological solutions in terms of their function and components. Their understanding is based on single components such as buttons and other familiar.

components. The pupils describe how a single component, which works as an input, controls the output directly and hence controls the function of the technological solution, without expressing anything about the process behind this or the other components involved. In some cases, the focus on single components and how they control the function causes pupils to identify technological solutions as programmed even if they not are. 
Interviewer: $[\ldots]$ do you think there are other things that are programmed?

Pupil 12: Yes, I guess lamps probably are, it's kind of when you push the button, then the lamp lights up.

Interviewer: Yes..?

Pupil 12: They must be programmed yes.

In the excerpt above, the pupil identifies a lamp as a programmed technological solution from a single component, its button, that directly controls the output, in this case to light up a lamp. In the excerpt below, the pupil also identifies a traffic light as a programmed technological solution from a single component, a button. This button, which in the pupil's description is controlled from an office, is directly connected to an output in the solution, a change in colour. Even though the pupil identifies the traffic light as programmed, the function is described as being controlled by a single component. In both these excerpts, the pupils do not express anything about the process that generates the output or anything about the structure of components between the input and the output. There seems to be a direct connection between the input, the buttons, and the function of the solution.

Interviewer: Traffic lights, yes?

Pupil 14: They are controlled like from an office, so it should go like this that now you change the colour type, and then it will be like that $[\ldots]$

Interviewer: $\mathrm{Mm}$, and how does a traffic light know when it is going to change colour?

$[\ldots]$

Pupil 14: A button. And then it will be that when you press a button like this say if this button is pressed then it will change colour like from red to yellow to green.

Interviewer: And then the programmed [part] in this, how do you think it is then?

Pupil 14: Then it's just that button and that it like goes from an office and that you don't like stand there and change it.

2. Single components interact which involves a flow In this category, the focus is still on single components and how they affect the output. However, in contrast to Category 1, pupils describe an interaction between single components and an output that involves a flow of something like pulses, waves, light, sound etc. The pupils do not express anything about the process of generating this flow and even though they are aware of a flow, they still see it in terms of the single components controlling the function of the solution.

In the excerpt below, the pupil draws parallels between the Micro:bit with its buttons that are programmed and the remote control that sends signals to the TV: when a certain button is pushed something happens. But the pupil points out that the remote control differs from the Micro:bit because there are no codes that are sent to the TV. When asked what these signals are, the pupil cannot explain what they are or anything about the process behind them. 
Interviewer: Mm then we'll talk about the remote control, I think. You say that this is programmed, what makes you think it's programmed?

Pupil 13: Yes, for example, as with the Micro:bit, there are buttons that you have programmed like a code but now there is no code for this then eh now it's only that you have programmed it on ... we did it with our robots and so on. We had another program that we sent some kind of ... because it sends signals to the TV like when the computer sends signals to the iPad or yes to the Micro:bit and then it's the remote control that's like a computer I guess but then I think, I do not know how this is programmed, but maybe it's like the Micro:bit, it's buttons so if you push a certain button something happens, and then I think it's about the same with the remote control but it has no codes that are sent. It runs more like on battery.

$[\ldots]$

Interviewer: Mm. These signals, what do they consist of? How does this work?

Pupil 13: I don't know, I can...well I really don't know.

Excerpts in this category indicate that pupils see the interaction between the buttons on the remote control and the TV. They also see that there is a flow of signals from the remote control to the TV but they do not express anything about how these signal are generated. In the excerpt below, the pupil describes how each button has a certain function that makes things happen. He is also on his way to discerning that the signal that is sent includes some kind of communication that is identified by the TV and affects the function of the TV.

Interviewer: You told me it's programmed, where is the programming?

Pupil 5: ...if you click certain buttons, that if you click the OFF and ON button, the TV will be turned on or off. The same thing if you click seven, then it will switch channel or if you want to raise and lower the volume. So each button has a certain function.

Interviewer: .... and how does this work? If you say, you press a button, how does the TV know that you want to watch channel four?

Pupil 5: It's like a signal from this remote control to the TV like when you control the TV with the remote control, it knows that the remote control has sent a signal to the TV that it is going to change the channel...

Both these excerpts indicate that pupils only see single components, the buttons, and even though they are aware of the flow between the buttons on the remote control and the TV, the pupils say that it is the buttons that make things happen and thus control the function.

3. A code and a flow of information are present The excerpts in this category show that the pupils see the structure of components in the technological solution and that there is a code involved. Even though there is an awareness of a code, they do not describe what the code represents. This category implies an understanding that the interaction between the components is based on the code and how the components are structured in the solution. The excerpts in this category also indicate that pupils see the flow of 
information between the components and how this flow affects the function of the technological solution. They see the components, rather than the code, as controlling the flow.

In the excerpt below, the pupil describes how a digital thermometer works: When the button is pushed, it gives an input that makes the sensor send signals to the display. The pupil sees that there is a code present and it is described as being involved in the interaction between the sensor and the output in the display but the pupil does not express anything about the logic in the code and what it represents. However, the pupil says that the components interact based on the code and the structure of components and that there is a flow of information ("signals") between the components that affects the output. But the signals are described as going directly between the components without passing the processor and its code. The flow seems to be controlled by the components rather than the code.

Pupil 1: It works so that if you push this button, the thermometer starts and begins to sense the temperature. Eh, depending on what kind of thermometer it is then, what's it called? Then it reads yes, but it senses the temperature and it's like a bath thermometer though it's more developed.

Interviewer: If you think of, you know when you measure the temperature, you'll see here in this small display what the temperature is. How is it possible that it can appear there? Why can you see it?

Pupil 1: It is coded so depending on what temperature it is, what digits come up here, it is made to show the temperature, for example if it senses 27 degrees, then it should show 27 degrees Celsius.

Pupil 1: Mm, they are somehow connected to each other you know. There is probably a sensor here [pointing at the tip of the thermometer] that sends signals to the display then what temperature it senses. And it's the same with this [pointing at the start button on the thermometer] which sends signals to the thermometer as yes to start it.

In the following excerpt about the remote control, the pupil says that it is not the buttons in themselves that contain the programming. There is something connected underneath the buttons, some kind of "hatch" that handles information when the button is pushed. The information then can be transferred from the remote control by sending signals that can be received and recognized by the TV as information. This excerpt indicates an understanding of the structure of components and how the interaction between them is a part of making information flow.

Pupil 6: ...in the... or under the buttons because I don't think it is the buttons in themselves that have the programming because it is when you push a button, there is always something underneath it that senses and then maybe...

Interviewer: What did you say?

Pupil 6: It is maybe the same here that it's connected then and then everything is gathered down into it so then when it is pushed down it's connected with another one so that they might be connected with a hatch with lots of info and then there 
is a battery in the remote control that makes it like get a kind of power so that it can work and transfer, or whatever you say, to the TV.

$[\ldots]$

Interviewer: Then, how does the TV know?

Pupil 6: Because it gathers it [...] there is a place where it receives a lot of info and there it knows that it's from the remote control [...]

4. The flow of information determines the function In this category, the pupils are able to give an idea of what the code represents and how it interacts with the structure of components based on the logic in the code to generate a flow of information. They have also discerned that the function of the components is to handle this flow of information and that the purpose of the code is to control the flow of information. The excerpts indicate that there is an understanding that the flow of information determines the function of the solution.

In the excerpt below, the pupil describes the different buttons on the remote control and how each button is connected to a script which includes directions for what is going to happen when a certain button is pushed. Further, there is a description of how the buttons on the car key interact with other components and the computer in the car by sending "signals" or "messages". These messages then affect other components in the car such as a motor that opens and closes the lock and fulfils the function of the technological solution. This pupil sees the structure and function of the components in the solution and how they interact in terms of what is written in the code, which is delivered as messages between them, and how these messages, the flow of information, determine the function of the solution.

Pupil 2: I think that there is maybe a sort of variable that has a name for each button, there are three buttons. And then we say the UNLOCK button that will unlock the car, there's a script for it that when the UNLOCK button is pushed on, ...signals are sent between or messages between them, the car and the key.

Interviewer: Well, if you think then, you say sends signals. Where do the signals go? You say the car here?

Pupil 2: ...it is possible to send messages on these chips eh so it will be like a message that will be sent to the car, because the car needs to have a computer inside it [...] a chip like that is probably connected to this [the car key] so if the message is received, the car is opened.

Interviewer: Yes and then when the computer in the car gets information, it unlocks the car, but how does this function? Can the computer unlock doors in a car?

Pupil 2: Well the computer is probably connected to these Makey Makey wires and there are certainly similar ones in the car that are connected to the computer and to a motor that has to...that the motor receives so the motor has two functions then, to close and to open, and when it receives this message or this wire is sending OPEN, like this one [shows the car key] has sent to the computer in the car, then it goes to the motor that says OPEN and then it opens... 


\subsection{The structural and referential aspects}

As a part of the analysis, the categories were analysed with the analytic tool of structural and referential aspects. The structural aspects relate to how the whole is discerned in relation to the parts that are discerned, and how the parts are related to each other and to the whole; and the referential aspects can be described as the meaning of the phenomenon, which in this case can be understood as the meaning of a programmed technological solution (Marton and Booth 1997). By analysing the units of excerpts with this tool, distinct differences emerged between pupils' understandings of different parts of a programmed technological solution, see Tables 1 and 2.

Table 1 Analysis of categories 'Micro:bit constructions' in relation to structural and referential aspects

\begin{tabular}{|c|c|c|c|c|}
\hline \multirow[b]{2}{*}{ Category } & \multicolumn{3}{|l|}{ Structural aspects } & \multirow{2}{*}{$\begin{array}{l}\text { Referential aspects } \\
\text { Function }\end{array}$} \\
\hline & Logic & Organisation & Interaction & \\
\hline $1 \mathrm{~A}$ & $\begin{array}{l}\text { No clear understanding } \\
\text { of what the code } \\
\text { represents }\end{array}$ & $\begin{array}{l}\text { Seeing the Micro:bit } \\
\text { construction as a } \\
\text { whole device, not } \\
\text { discerning the } \\
\text { components }\end{array}$ & $\begin{array}{l}\text { Describing an interaction } \\
\text { between the code and } \\
\text { the device }\end{array}$ & $\begin{array}{l}\text { Describing how the } \\
\text { interaction between } \\
\text { the code and the } \\
\text { device affects the } \\
\text { function of the } \\
\text { technological } \\
\text { solution }\end{array}$ \\
\hline $2 \mathrm{~A}$ & $\begin{array}{l}\text { Describing what the } \\
\text { code and its } \\
\text { structure represent }\end{array}$ & $\begin{array}{l}\text { Discerning the } \\
\text { components and } \\
\text { expressing something } \\
\text { about how they work }\end{array}$ & $\begin{array}{l}\text { Describing an } \\
\text { interaction between } \\
\text { the code and the } \\
\text { components based } \\
\text { on the logic in the } \\
\text { code and how the } \\
\text { components work }\end{array}$ & $\begin{array}{l}\text { Describing how the } \\
\text { interaction between } \\
\text { the code and the } \\
\text { components affects } \\
\text { the function of the } \\
\text { technological } \\
\text { solution }\end{array}$ \\
\hline $3 \mathrm{~A}$ & $\begin{array}{l}\text { Describing what the } \\
\text { code and its } \\
\text { structure represent }\end{array}$ & $\begin{array}{l}\text { Discerning the structure } \\
\text { of components in the } \\
\text { technological } \\
\text { solution }\end{array}$ & $\begin{array}{l}\text { Describing an interaction } \\
\text { between the code and } \\
\text { the components based } \\
\text { on the logic in the } \\
\text { code and the structure } \\
\text { of the components, } \\
\text { which generates a } \\
\text { flow of something } \\
\text { such as pulses, waves, } \\
\text { light, sound etc. }\end{array}$ & $\begin{array}{l}\text { Describing how the } \\
\text { flow affects the } \\
\text { function of the } \\
\text { technological } \\
\text { solution }\end{array}$ \\
\hline $4 \mathrm{~A}$ & $\begin{array}{l}\text { Describing what the } \\
\text { code and its structure } \\
\text { represent and how } \\
\text { the code controls the } \\
\text { flow of information }\end{array}$ & $\begin{array}{l}\text { Discerning that the } \\
\text { function of the } \\
\text { components is to } \\
\text { handle information } \\
\text { in the technological } \\
\text { solution }\end{array}$ & $\begin{array}{l}\text { Describing an interaction } \\
\text { between the code and } \\
\text { the components based } \\
\text { on the logic in the } \\
\text { code and the structure } \\
\text { and function of the } \\
\text { components which } \\
\text { generate a flow of } \\
\text { information that is } \\
\text { controlled by the code }\end{array}$ & $\begin{array}{l}\text { Describing how the } \\
\text { flow of information } \\
\text { determines the } \\
\text { function of the } \\
\text { technological } \\
\text { solution }\end{array}$ \\
\hline
\end{tabular}


Table 2 Analysis of categories 'Technological solutions in everyday life' in relation to structural and referential aspects

\begin{tabular}{|c|c|c|c|c|}
\hline \multirow[b]{2}{*}{ Category } & \multicolumn{3}{|l|}{ Structural aspects } & \multirow{2}{*}{$\begin{array}{l}\text { Referential aspects } \\
\text { Function }\end{array}$} \\
\hline & Logic & Organisation & Interaction & \\
\hline $1 \mathrm{~B}$ & - & $\begin{array}{l}\text { Focusing on single } \\
\text { components }\end{array}$ & $\begin{array}{l}\text { Describing an } \\
\text { interaction between } \\
\text { single components }\end{array}$ & $\begin{array}{l}\text { Describing how single } \\
\text { components control } \\
\text { the function of the } \\
\text { technological solution }\end{array}$ \\
\hline $2 \mathrm{~B}$ & - & $\begin{array}{l}\text { Focusing on single } \\
\text { components }\end{array}$ & $\begin{array}{l}\text { Describing an interaction } \\
\text { between single } \\
\text { components and } \\
\text { seeing a flow of } \\
\text { something between } \\
\text { the components such } \\
\text { as pulses, waves, light, } \\
\text { sound etc. }\end{array}$ & $\begin{array}{l}\text { Describing how single } \\
\text { components control } \\
\text { the function of the } \\
\text { technological } \\
\text { solution }\end{array}$ \\
\hline $3 \mathrm{~B}$ & $\begin{array}{l}\text { Awareness of a code } \\
\text { but not describing } \\
\text { what the code } \\
\text { represents }\end{array}$ & $\begin{array}{l}\text { Discerning the } \\
\text { structure of } \\
\text { components in the } \\
\text { technological } \\
\text { solution }\end{array}$ & $\begin{array}{l}\text { Describing an } \\
\text { interaction between } \\
\text { the components } \\
\text { based on the code } \\
\text { and the structure of } \\
\text { components and } \\
\text { relating this to a flow } \\
\text { of information which } \\
\text { is controlled by the } \\
\text { components }\end{array}$ & $\begin{array}{l}\text { Describing how the } \\
\text { flow of information } \\
\text { affects the function } \\
\text { of the technological } \\
\text { solution }\end{array}$ \\
\hline $4 \mathrm{~B}$ & $\begin{array}{l}\text { Describing what the } \\
\text { code and its } \\
\text { structure represent } \\
\text { and how the code } \\
\text { controls the flow } \\
\text { of information }\end{array}$ & $\begin{array}{l}\text { Discerning that the } \\
\text { function of the } \\
\text { components is to } \\
\text { handle information } \\
\text { in the technological } \\
\text { solution }\end{array}$ & $\begin{array}{l}\text { Describing an interaction } \\
\text { between the code and } \\
\text { the components based } \\
\text { on the logic in the } \\
\text { code and the structure } \\
\text { and function of the } \\
\text { components, which } \\
\text { generates a flow of } \\
\text { information which is } \\
\text { controlled by the code }\end{array}$ & $\begin{array}{l}\text { Describing how the } \\
\text { flow of information } \\
\text { determines the } \\
\text { function of the } \\
\text { technological } \\
\text { solution }\end{array}$ \\
\hline
\end{tabular}

\subsection{The common outcome space}

The analysis of the two outcome spaces based on the structural and referential aspects constituted a common integrated outcome space, see Fig. 4. Pupils discern different parts of the phenomenon depending on the contexts that are presented.

In the Micro:bit context, there is an unclear understanding in Category 1 of the code and no discernment of the components. The code and the structure of components are treated as black boxes, which is probably the reason for the vague understanding of the function. In Category 2 in the same context, the logic in the code and the discernment of the components and how they work are included, which can be seen as critical differences in understanding between Categories 2 and 1. This makes it possible to understand how the code and the components interact and affect the function. Category 


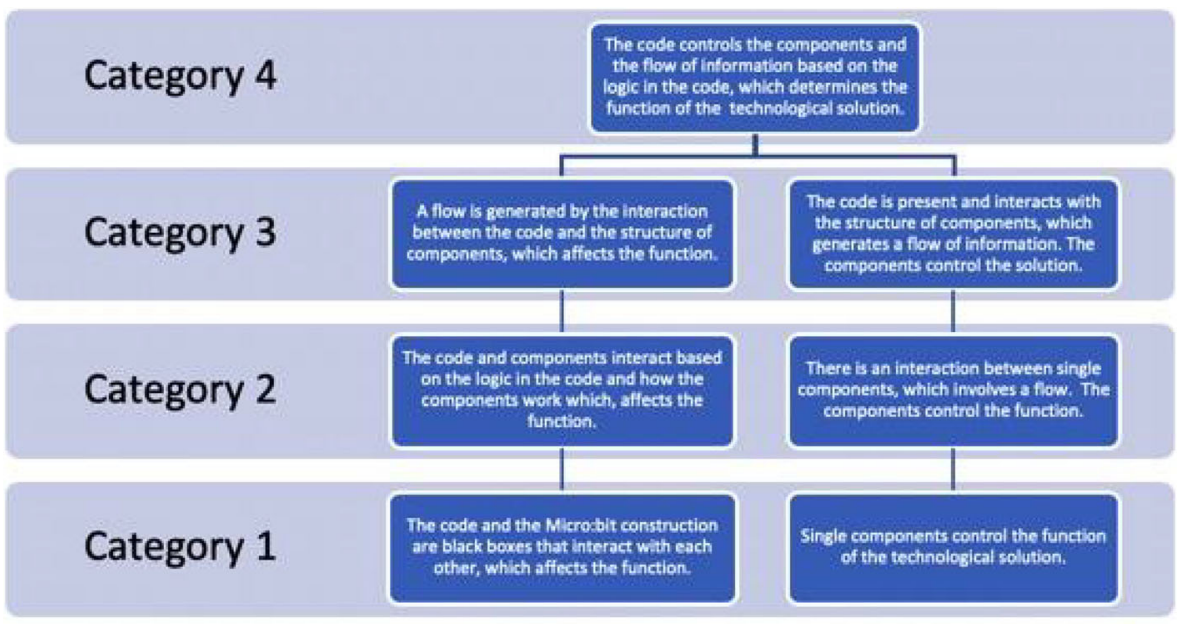

Contexts

A. Micro:bit constructions

B. Technological solutions in everyday life

Fig. 4 The common outcome space

3 includes the discernment of a flow that is generated by the interaction of the code and the structure of components, which is a critical difference in understanding from Category 2. In the context of everyday solutions, the understanding in Category 1 is based on single components that control the function. In Category 2, the discernment of a flow is added, which is a critical difference from Category 1. In Category 3, there is an awareness of a code and the structure of components, which is critical for seeing the flow as information. The code is treated as a black box, which is probably the reason that the pupils still cannot see that it is the code that controls the flow of information, and not the components. The different understandings in the two contexts then merge into one in Category 4, which includes the discernment of the logic in the code and how it controls the flow of information, the function and structure of components, and the interaction that generates a flow of information that determines the function. All these critical aspects need to be discerned at the same time in order to reach a more complex and powerful understanding of programmed technological solutions.

\section{Discussion}

The point of departure of this study is the overall aim within technology education to develop pupils' understanding of technological solutions in everyday life, of which programmed technological solutions form a great part. This aim is bi-directional since it includes both the ability to identify and analyse existing technological solutions, and the ability to design new technological solutions. These directions are closely intertwined, since both are based on the ability to see and understand the function that will fulfil a particular need and how this function is realized by an appropriate, physical 
structure of components. In line with the aim in this study, the results then contribute a deeper insight into pupils' qualitatively different understandings of programmed technological solutions, which will provide an important basis for organizing teaching that develops pupils' understanding of programmed technological solutions.

\subsection{Systems thinking - an important key}

If pupils are to be able to understand existing programmed technological solutions, and also be able to design new ones, a prerequisite is that they discern and understand both the physical and the functional structure of a programmed technological solution. Previous research (Booth Sweeney and Sterman 2007; Koski and de Vries 2013; Svensson 2011) reports how systems thinking based on understanding the parts, how the parts interact, and the system as a whole, facilitates pupils' understanding of technological solutions. The results from the present study show that pupils are approaching the programmed technological solutions with different levels of systems thinking. In Category 1A, they are not able to go into detail, they "black box" the code and the structure of components and describe what the interaction between them results in. It seems that this black boxing strategy gives them a vague understanding of the function, even if they do not understand all the parts. This is, however, not a sustainable strategy if they are to be able to control their own designs with programming, since it becomes difficult to realize the function if you do not understand all the parts and how they interact. In Category 1B, pupils focus on single components and the function of the technological solution. Koski and de Vries (2013) describe this as a user-driven approach based on pupils' experience of using the technological solution, which they propose as a starting point when introducing systems thinking in teaching. In Categories $2 \mathrm{~A}, 2 \mathrm{~B}, 3 \mathrm{~A}$ and $3 \mathrm{~B}$, it can be seen that pupils discern more and more of the parts. They are able to open up the black boxes and go into detail in some cases, although not in others. Finally in Category 4, they have reached a level of systems thinking where they are able to describe in more detail the interaction between the structure of the components and the logic in the code, and how the code controls the flow of information that determines the function. This result indicates that systems thinking may be an important key for developing pupils' understanding of programmed technological solutions.

\subsection{What is presented and appresented}

Systems thinking may facilitate the understanding of a programmed technological solution, but pupils need to discern all the parts involved. One of the main results from this study is the pupils' different approaches to programmed technological solutions in the two prepared contexts, and what parts the pupils discern in relation to the contexts. As can be seen, pupils' understandings of programmed technological solutions differ in the lower categories (1-3), depending on what is present in the contexts. The visible parts, like the code in the Micro:bit constructions or the buttons in the everyday solutions, are prominent, while invisible parts like the flow of information are abstract and difficult to grasp. The difficulties seem to be in discerning what is invisible, or appresented, in the contexts. In the everyday solutions, the pupils do not initially discern that there is a code involved, even though they state that the technological 
solution is programmed. In the Micro:bit constructions, the components are not initially discerned, nor is the flow discerned in the lower categories. There are pupils in the higher categories who discern these parts, even though they are exposed to the same contexts as other pupils. These pupils' understandings are constituted both from parts that are present and parts that are appresent. The discernment of all these parts gives the prerequisites to move away from the contextual details and generalize the understanding on the basis of both the parts that are present and appresent.

The results also show qualitative differences between the categories, within each context, due to what is discerned and not discerned. Even though pupils discern different aspects at different levels in the two contexts, there are similar critical aspects that need to be discerned to reach the highest level of understanding in both contexts. Discerning the structure of components is critical for understanding how the function is realized, which includes an understanding of how the components work and their function in the technological solution. It is also critical to discern the logic in the code, and how the code controls the components and the flow of information that determines the function. Similar results are reported by Slangen et al. (2010) and Mioduser et al. (1996) when pupils learn to control technological solutions by using programming.

Systems thinking may be an important key to developing pupils' understanding of programmed technological solutions. This requires discernment of all the parts, both presented and appresented. As can be seen from the results, some pupils are not able to discern all parts in the different contexts, and some of these parts are critical to discern in order to develop a more powerful understanding of programmed technological solutions. This result has implications when using concrete programming materials in teaching to obtain a generalized understanding about programmed technological solutions and digital technology.

\subsection{Didactical implications}

Generally, concrete programming materials are used in teaching to facilitate pupils' learning about abstract phenomenon. This can mean both understanding basic programming concepts but also, as in technology education, understanding the physical structure of components in a programmed technological solution and their interaction with the code to realize a specific function. The results show that the materials contribute to only some parts of the programmed technological solutions being initially discerned and understood. This result is in line with previous studies (Ivarsson 2003; Lye and Koh 2014; Pea 1983; Rolandsson 2015) that report how pupils do not manage to make relevant connections between concrete programming material and the abstract concepts the material represents. It also seems that pupils transfer their vague understanding of certain parts from the programming materials to everyday programmed solutions. An example of this is when pupils describe buttons as components representing a programmed technological solution, as in Category 1B. This may have its origin in different programming materials, where buttons are commonly used as input: you push the button and this affects the output, i.e. something happens. Even though pupils know that there is a code involved in the programming material, they have not discerned that the purpose of the code is to control the components and the 
flow of information. When they transfer this vague understanding of buttons to an everyday programmed solution, they see the buttons as controlling the function, since the code is appresented and not discerned. There are even pupils who state that there is no code involved even though they have identified the technological solution as programmed.

When pupils meet a programmed technological solution in a new context, their understanding seems to be based on the discerned parts from a previous context. If all parts are not discerned and understood in the previous context, this lack of understanding seems to be transferred to the new context. If a concrete programming material is used to represent programmed technological solutions, then teaching should focus on facilitating the discernment of all the parts of the phenomenon in that context. A more powerful understanding of programmed technological solutions in that context might allow the pupil to understand programmed technological solutions in a more powerful way in a new context, i.e. everyday programmed solutions. In order to allow pupils to generalize the understanding of programmed technological solutions and transfer it to new contexts, the teacher needs to provide opportunities to see the phenomenon, programmed technological solutions, in different contexts, where both the similarities and the differences between the contexts are highlighted, based on the presented and appresented parts. This is line with Marton's reasoning (2006), that the discerned differences and similarities between the contexts makes it possible to generalize the understanding of a phenomenon and transfer it to new contexts .

\subsection{Summary}

It cannot be taken for granted that concrete programming materials like Micro:bit automatically develop pupils' understanding of programmed technological solutions in everyday life. Pupils approach these two contexts differently based on what parts are discerned in the contexts. The parts that are critical to discern in both of the contexts are the physical structure of components in the technological solution, how the components work and what their function is in the solution, as well as the logic in the code and how it controls the components and the flow of information that determines the function of the solution. To be able to transfer and generalize the understanding of programmed technological solutions between the contexts, pupils have to discern all the parts, both presented and appresented, and they also have to discern the differences and the similarities between the contexts. These results have implications for teaching with concrete programming materials, suggesting that it is important to focus on visualizing and highlighting the parts that are critical to discern, and addressing the similarities and the differences between contexts, in order to allow pupils to reach a generalized understanding that can be transferred between the different contexts where the phenomenon exists. In this, systems thinking may be an important key to understanding a programmed technological solution's physical structure and its function.

The results from this study indicate that further research is required in order to learn more about what characterizes an understanding of the structure and function of programmed technological solutions, not only when analysing existing technological solutions but also when designing new ones. Further studies also need to focus on how this can be addressed in teaching. 
Acknowledgements Open access funding provided by University of Gothenburg.

Open Access This article is distributed under the terms of the Creative Commons Attribution 4.0 International License (http://creativecommons.org/licenses/by/4.0/), which permits unrestricted use, distribution, and reproduction in any medium, provided you give appropriate credit to the original author(s) and the source, provide a link to the Creative Commons license, and indicate if changes were made.

\section{References}

Adawi, T., Berglund, A., Ingerman, Å., \& Booth, S. (2001). On context in phenomenographic research on understanding heat and temperature. 9th Earli Conference, Fribourg, August 2001, Fribourg, Switzerland.

Balanskat, A., \& Engelhardt, K. (2015). Computing our future: Computer programming and coding - Priorities, school curricula and initiatives across Europe. Retrieved from http://www.eun.org/resources/detail?publicationID=661. Accessed 5 Sept 2017

Booth Sweeney, L., \& Sterman, J. D. (2007). Thinking about systems: Student and teacher conceptions of natural and social systems. System Dynamics Review, 23(2-3), 285-311. https://doi.org/10.1002/sdr.366.

de Vries, M. J. (2005). Teaching about technology: An introduction to the philosophy of Technology for nonphilosophers. Dordrecht: Springer.

Ginestié, J. (2018). Using computer technologies in design and technology education: Teachinglearning process. In M. J. de Vries (Ed.), Handbook of Technology Education (pp. 403-418). https://doi.org/10.1007/978-3-319-44687-5_31.

Grover, S., \& Basu, S. (2017). Measuring student learning in introductory block-based programming: Examining misconceptions of loops, variables, and Boolean logic. Proceedings of the Conference on Integrating Technology into Computer Science Education, ITiCSE, 267-272. https://doi.org/10.1145 /3017680.3017723.

Hubwieser, P., Armoni, M., Giannakos, M., \& Mittermeir, R. (2014). Perspectives and visions of computer science education in primary and secondary (K-12) Schools. ACM Transactions on Computing Education (TOCE), 14(2), 1-9.

Ingelstam, L. (2012). System : att tänka över samhälle och teknik (2. uppl.). Retrieved from http://libris.kb.se/hitlist?d=libris\&q=91-89184-28-9\&f=simp\&spell=true \&hist=true $\& \mathrm{p}=1$. Accessed 12 Feb 2018

Ivarsson, J. (2003). Kids in zen: Computer-supported learning environments and illusory intersubjectivity. Education, Communication \& Information, 3(3), 383-402. https://doi.org/10.1080 /1463631032000149692.

Kalelioglu, F. (2015). A new way of teaching programming skills to K-12 students: Code.org. Computers in Human Behavior, 52, 200-210.

Kalelioglu, F., \& Gülbahar, Y. (2014). The effects of teaching programming via scratch on problem solving skills: A discussion from learners' perspective. Informatics in Education, 13(1), 33-50.

Kjällander, S., Åkerfeldt, A., \& Petersen, P. (2016). Översikt avseende forskning och erfarenheter kring programmering i förskola och grundskola. Retrieved from Skolverket website: http://omvarld.blogg. skolverket.se/wp-content/uploads/sites/2/2016/06/oversikt_programmering_i_skolan.pdf. Accessed 13 Oct 2017

Koski, M.-I., \& de Vries, M. (2013). An exploratory study on how primary pupils approach systems. International Journal of Technology and Design Education, 23(4), 835-848. https://doi.org/10.1007 /s10798-013-9234-Z.

Lye, S. Y., \& Koh, J. H. L. (2014). Review on teaching and learning of computational thinking through programming: What is next for K-12? Computers in Human Behavior, 41, 51-61. https://doi.org/10.1016 j.chb.2014.09.012.

Marton, F. (2006). Sameness and difference in transfer. Journal of the Learning Sciences, 15(4), $499-535$. https://doi.org/10.1207/s15327809j1s1504_3.

Marton, F. (2015). Necessary conditions of learning. New York: Routledge.

Marton, F., \& Booth, S. (1997). Learning and awareness. Mahwah: Erlbaum.

McCracken, M., Almstrum, V., Diaz, D., Guzdial, M., Hagan, D., Kolikant, Y., et al. (2001). A multi-national, multi-institutional study of assessment of programming skills of first-year CS students. ACM SIGCSE Bulletin, 33(4), 125-180. https://doi.org/10.1145/572139.572181. 
Mioduser, D., Venezky, R. L., \& Gong, B. (1996). Students' perceptions and designs of simple control systems. Computers in Human Behavior, 12(3), 363-388. https://doi.org/10.1016/0747-5632(96)00014-3.

Mitcham, C. (1994). Thinking through technology: The path between engineering and philosophy. Chicago: Univ. of Chicago Press.

Papert, S. (1993). Mindstorms: children, computers, and powerful ideas (2nd ed./with an introduction by John Sculley and a new preface by the author.). New York: Basic books.

Passey, D. (2017). Computer science (CS) in the compulsory education curriculum: Implications for future research. Education and Information Technologies, 22(2), 421-443.

Pea, R. D. (1983). Logo programming and problem solving. [Technical Report No. 12.]. Bank street College of Education. New York. Center for Children and Technology.

Pea, R. D., \& Kurland, D. M. (1984). On the cognitive effects of learning computer programming. New Ideas in Psychology, 2(2), 137-168. https://doi.org/10.1016/0732-118X(84)90018-7.

Robins, A., Rountree, J., \& Rountree, N. (2003). Learning and teaching programming: A review and discussion. Computer Science Education, 13(2), 137-172. https://doi.org/10.1076/csed.13.2.137.14200.

Rolandsson, L. (2015). Programmed or not: A study about programming teachers' beliefs and intentions in relation to curriculum: programmering $i$ skolan från ett lärarperspektiv. TRITA-ECE, 2015. Retrieved from http://kth.diva-portal.org/smash/get/diva2:791197/FULLTEXT02.pdf. Accessed 1 Sept 2017

Rush Hovde, M., \& Renguette, C. C. (2017). Technological literacy: A framework for teaching technical communication software tools. Technical Communication Quarterly, 26(4), 395-411. https://doi.org/10.1080/10572252.2017.1385998.

Sentance, S., \& Csizmadia, A. (2017). Computing in the curriculum: Challenges and strategies from a teacher's perspective. Education and Information Technologies, 22(2), 469-495.

Skolverket. (2017a). Få syn på digitaliseringen på grundskolenivå: ett kommentarmaterial till läroplanerna för förskoleklass, fritidshem och grundskoleutbildning. Stockholm: Skolverket Wolters Kluwer.

Skolverket. (2017b). Läroplan för grundskolan, förskoleklassen och fritidshemmet 2011: reviderad 2017. Stockholm: Skolverket.

Slangen, L., van Keulen, H., \& Gravemeijer, K. (2010). What pupils can learn from working with robotic direct manipulation environments. International Journal of Technology and Design Education, 21(4), 121. https://doi.org/10.1007/s10798-010-9130-8.

Svensson, M. (2011). Att urskilja tekniska system: didaktiska dimensioner i grundskolan. Linköping: LiUTryck Retrieved from http://liu.diva-portal.org/smash/get/diva2:382726/FULLTEXT01.pdf. Accessed 5 Mar 2018

Trigwell, K. (2006) Phenomenography: An Approach to Research into Geography Education. Journal of Geography in Higher Education 30 (2), 367-372. https://doi.org/10.1080/03098260600717489

Webb, M., Davis, N., Bell, T., Katz, Y., Reynolds, J., Chambers, N., \& Sysło, D. (2017). Computer science in K-12 school curricula of the 21st century: Why, what and when? Education and Information Technologies, 22(2), 445-468.

Publisher's note Springer Nature remains neutral with regard to jurisdictional claims in published maps and institutional affiliations. 